\title{
Mitral stenosis with high left ventricular diastolic pressure
}

\author{
T. A. TRAILL, M. G. ST. JOHN SUTTON, AND D. G. GIBSON \\ From the Cardiac Department, Brompton Hospital, London
}

SUMMARY Three patients with mitral stenosis are described, in whom the haemodynamic findings at cardiac catheterisation were more suggestive of left ventricular myocardial disease, in that the left ventricular diastolic pressure was high and the mitral valve gradient small. However, their echocardiograms showed abnormal wall movement during diastole characteristic of severe inflow obstruction, with slow and protracted filling, and at operation mitral stenosis was confirmed. Left ventricular wall stress was estimated throughout the cardiac cycle in one patient, and the diastolic stress-strain relation shown to be abnormal. The effects of mitral stenosis on left ventricular function are complex, and are not explicable simply by reduction in size of the mitral orifice.

It has been said that 'the fundamental hemodynamic expression of mitral stenosis is the presence of an elevated left atrioventricular filling pressure gradient' (Braunwald et al., 1955). Therefore, in patients with this lesion in whom there is doubt as to its severity, whether because of the paucity of physical signs or because of the suspicion of left ventricular disease, it may be helpful to measure such a gradient by cardiac catheterisation.

In recent years, echocardiography has made it possible to assess the anatomical state of the valve. The signs of rheumatic involvement are broadening of the cusp echoes signifying thickening, forward movement in diastole of the posterior cusp, which indicates cusp fusion, reduced amplitude of movement when the valve or chordae are particularly rigid, and slow early diastolic closure. However, to judge the extent of physiological disturbance, it is more satisfactory to estimate the degree of obstruction to left ventricular filling from the rate of separation of the endocardial surfaces of the posterior left ventricular wall and the left side of the septum measured continuously throughout diastole (Gibson and Brown, 1973). This technique has been used to demonstrate both reduction in peak rate of filling, and disturbance of its normal pattern.

The result has been that in some cases where both cardiac catheterisation and echocardiography have been performed, the results have been discordant. We report 3 such patients in whom catheter results

Received for publication 29 June 1978 were such as to suggest left ventricular disease by virtue of a high left ventricular end-diastolic pressure and small mitral valve gradient, whereas the echocardiogram was diagnostic of severe disorganisation of the valve and slow left ventricular filling. They all underwent successful surgery.

\section{Methods}

\section{ECHOCARDIOGRAPHY}

Echocardiograms were recorded with the patients semi-supine and partially rotated to the left. A Smith-Kline ultrasonoscope was used and the permanent record made direct on to Polaroid film or with a Cambridge Instruments strip-chart recorder.

The records were digitised for computer processing as described by Gibson and Brown (1973) and Upton et al. (1976). Continuous plots were obtained of transverse left ventricular dimension, its rate of change, and instantaneous mitral leaflet velocity (Fig. 1). The normal (mean \pm standard deviation) peak diastolic rate of change of dimension is $16 \pm 3 \mathrm{~cm} / \mathrm{s}$; in a group of patients with unequivocal mitral stenosis this was reduced to 3 to $11 \mathrm{~cm} / \mathrm{s}$. In normal subjects most filling occurs in the first third of diastole, the rate of wall separation declining to 20 per cent of its peak value within $115 \pm 20 \mathrm{~ms}$, but with mitral stenosis this pattern is changed for there is no distinct rapid filling phase and dimension continues to increase at almost its peak rate throughout diastole. The peak rate of early diastolic mitral valve closure is 130 to $370 \mathrm{~mm} / \mathrm{s}$ in normal subjects, 

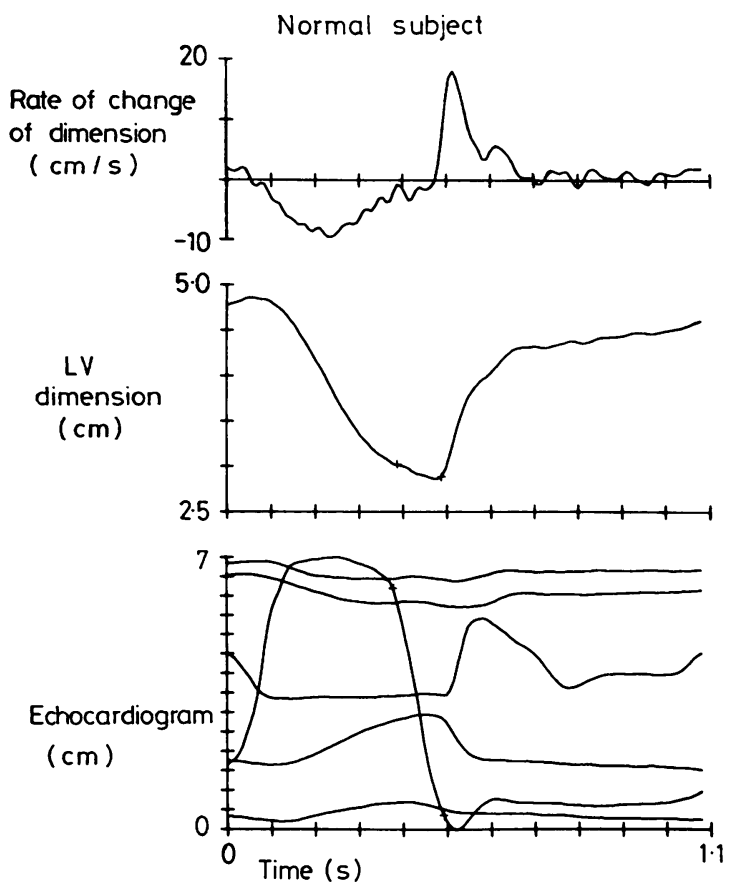

Fig. 1 Normal subject: plots of left ventricular cavity dimension and its rate of change derived from the digitised echocardiogram reproduced in the lowest panel. The apex cardiogram is superimposed. The crosses mark times of aortic valve closure and mitral opening.

and is reduced to below $80 \mathrm{~mm} / \mathrm{s}$ in most patients with mitral stenosis.

\section{CARDIAC CATHETERISATION}

Patients were studied fasting and at rest after pre-medication with $200 \mathrm{mg}$ amylobarbitone given orally one hour before. Fluid filled catheters were used with Bell and Howell transducers for the routine pressure measurements, which were referred to zero taken at the 'mid-chest', that is the midpoint of a vertical line between the sternal angle and the top of the patient table. The static accuracy of the system is assessed as within 2 per cent, and the frequency response is flat to $10 \mathrm{~Hz}$. Left atrial pressure was measured directly by transseptal puncture in case 1 , and as the pulmonary capillary ('wedge') pressure in the others. Zero and calibration were rechecked at the time of recording simultaneously the left ventricular and left atrial pressures. All the pressure records were taken before injection of angiographic dye. When estimating the mitral valve gradient the wedge pressure record was advanced so as to line up the ' $y$ ' descent with the fall in left ventricular pressure. In case 2 , in whom left ventricular stress analysis was performed, left ventri- cular pressure was also measured using a Millar catheter tip micromanometer and recorded simultaneously with an echocardiogram. The results were analysed as described by Gibson and Brown (1974). Cardiac index was estimated by the direct Fick method. Assumed values for oxygen uptake were taken from Robertson and Reid (1952).

Case 1

A South African Asian woman was investigated at Brompton Hospital at the age of 41. She had rheumatic fever as a child, and at the age of 22, having been asymptomatic for a year, she had a closed mitral valvotomy, with good effect. She had uneventful pregnancies when she was 28 and 31 , but when she was 36, coinciding with the onset of atrial fibrillation, she began again to notice breathlessness on exertion and tiredness. At about the same time she had a left axillary embolus. Over the succeeding years her state worsened and 4 years later, when she was admitted for investigation, she was breathless on minor exertion, NYHA grade 3, and orthopnoeic.

She was thin and dyspnoeic on the least effort. The heart rate was $80 / \mathrm{min}$ in atrial fibrillation. The peripheral pulses were of small volume and the arterial pressure was $110 / 80 \mathrm{mmHg}$. The jugular venous pressure was raised to the angle of the jaw with prominent systolic pulsation, and the liver was enlarged, pulsatile, and tender. There was clinical right ventricular hypertrophy and the first heart sound was palpable. The pulmonary closure sound. was accentuated and there was a short, quiet (grade 1/4) mitral diastolic murmur, but no opening snap. There were no adventitious sounds over the lungs. or peripheral oedema.

The chest $x$-ray film showed moderate increase in overall heart size, with enlargement of the left atrium and prominent upper lobe veins. The electrocardiogram confirmed atrial fibrillation and showed right ventricular hypertrophy.

The echocardiogram (Fig. 2) showed mitral valve thickening, cusp fusion-the posterior cusp moved forward in diastole-and reduction of the peak mitral diastolic closure rate to $22 \mathrm{~mm} / \mathrm{s}$. The peak rate of separation of the endocardial surfaces of the septum and posterior left ventricular wall was reduced to $6 \mathrm{~cm} / \mathrm{s}$, and the pattern of dimension increase was typical of mitral stenosis (Fig. 3).

The results obtained at cardiac catheterisation are displayed in the Table. There was pulmonary hypertension and the left atrial pressure was raised. However, there was no diastolic gradient between left atrium and ventricle as the two pressures were identical throughout diastole. The end-diastolic pressure was $28 \mathrm{mmHg}$. The left atrial $\mathrm{V}$ wave was $42 \mathrm{mmHg}$, but there was no mitral regurgitation 


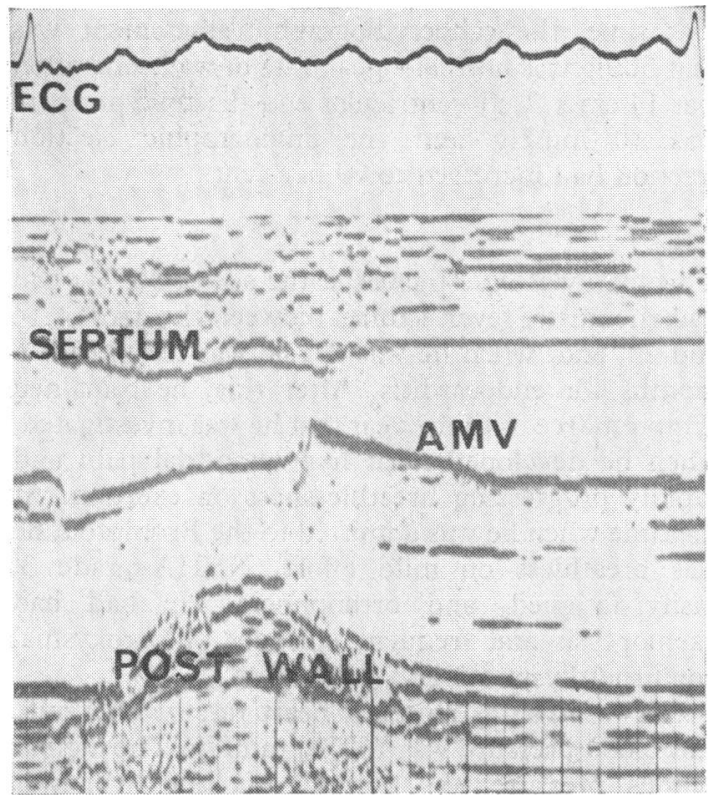

Fig. 2 Case 1: echocardiogram showing the endocardium of the posterior side of the ventricular septum, the posterior wall, and the anterior cusp of the mitral valve $(A M V)$.

demonstrable on cineangiography.

The catheterisation findings suggested that there was no mitral valve disease, but she was referred for surgery because of the echocardiogram, and at operation was found to have thickened mitral leaflets with a small orifice. The valve was excised and replaced with a No. $3 \mathrm{M}$ Starr-Edwards prosthesis. Two years after operation she reports normal exercise tolerance and no orthopnoea or fatigue.

\section{Case 2}

An English housewife was aged 39 at the time of investigation. She had chorea at the age of 11 and first developed symptoms of heart disease during the first of her pregnancies, which were when she was 23,27 , and 31 . During each she was breathless on exertion. When she was 35 , having again become
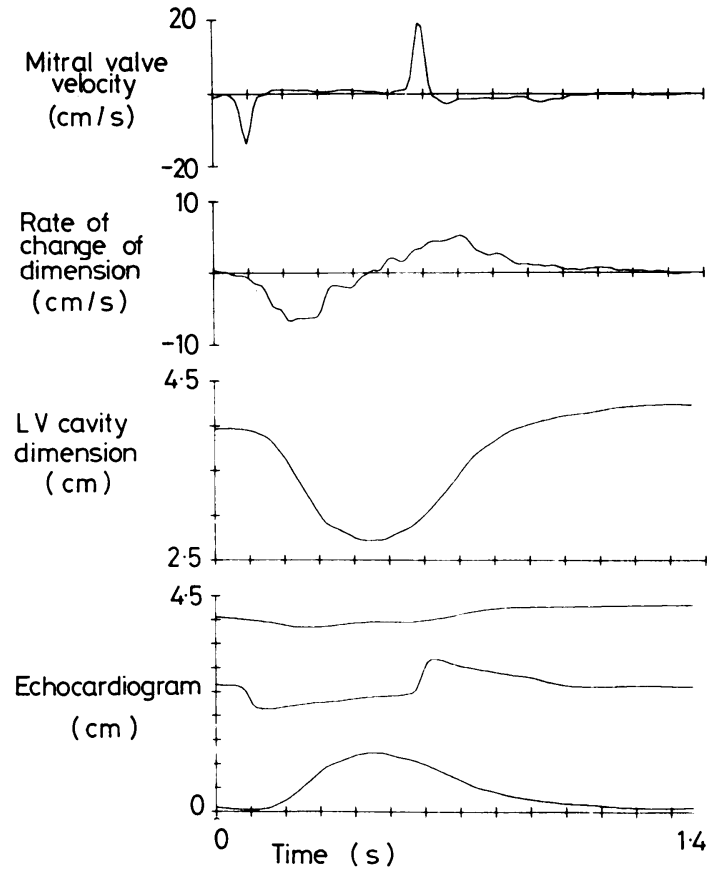

Fig. 3 Case 1: plots from the digitised echocardiogram showing, from below upwards, the original echocardiogram, the left ventricular dimension, its rate of change, and the rate of change of position of the anterior mitral valve cusp.

breathless and developed haemoptysis and paroxysmal nocturnal dyspnoea, closed mitral valvotomy was performed with good initial relief of her symptoms. In the next few years, however, she deteriorated again and she was readmitted for investigation 4 years after the operation. At that time she was breathless on moderate exertion, NYHA grade $2 b$, was orthopnoeic, and had frequent episodes of nocturnal dyspnoea and palpitation.

Abnormal physical signs were confined to the cardiovascular system. The heart rate was $110 / \mathrm{min}$, in atrial fibrillation. There were no signs of fluid retention. The cardiac impulse was unremarkable,

Table Haemodynamic results at catheterisation

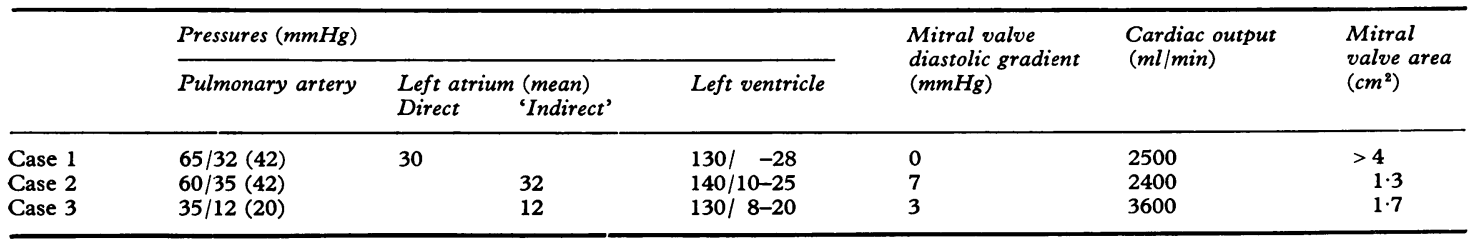

Note: The two diastolic left ventricular pressures given are early and end-diastolic figures. The figure in brackets after the pulmonary artery systolic and diastolic pressures is the mean. Mitral valve area refers to the estimate obtained using the formula of Gorlin and Gorlin (1951). 
but on auscultation there was accentuation of the pulmonary component of the second heart sound, an opening snap, and grade $2 / 4$ mid-diastolic murmur. The chest $x$-ray film showed slight cardiomegaly, left atrial enlargement, and upper lobe venous engorgement. The electrocardiogram confirmed atrial fibrillation and showed right ventricular hypertrophy.

The echocardiogram showed that the peak diastolic closure rate of the anterior mitral valve was reduced $(9 \mathrm{~mm} / \mathrm{s})$ and there was forward movement in diastole of the posterior cusp. Peak rate of increase in transverse cavity dimension was reduced to $5 \mathrm{~cm} / \mathrm{s}$ and outward wall movement continued throughout diastole (Fig. 4).

Cardiac catheterisation data are displayed in the Table. There was a small measured mitral valve gradient of $7 \mathrm{mmHg}$ (mean) and the left atrial and ventricular pressures equalised at end-diastole at $25 \mathrm{mmHg}$. Left ventricular wall excursion was reduced; the estimated ejection fraction (based on single plane angiogram) was 38 per cent.

Although the measured gradient was slight and there were features to suggest left ventricular disease, it was eventually decided to recommend surgery. At open exploration the mitral valve orifice was estimated to measure $1 \mathrm{~cm}$ by $0.5 \mathrm{~cm}$. It was possible to conserve the valve by commissurotomy and separation of the fused chordae tendineae.

In the 3 years since her operation, she has fared well, with breathlessness only on severe exertion. She consented to repeat left heart catheterisation, which was performed 4 months after surgery. At that time, the echocardiographic assessment was that filling was normal- peak rate of wall separation was $14 \mathrm{~cm} / \mathrm{s}$. Left ventricular end-diastolic pressure was $10 \mathrm{mmHg}$ and the angiographic ejection fraction had increased to 70 per cent.

\section{Case 3}

This man was investigated at the age of $36 . \mathrm{He}$ had had rheumatic fever 4 times between the ages of 14 and 25 , and, when he was 27 , he was treated for 6 months for endocarditis. After this, he remained symptom free until the year that he was investigated, when he developed right hypochondrial pain and rapidly progressing breathlessness on exertion. At the time when he was admitted to the Brompton, he was breathless on mild effort, NYHA grade 3, easily fatigued, and orthopnoeic. He had had haemoptysis and frequent episodes of paroxysmal nocturnal dyspnoea and palpitation.

He was in sinus rhythm; heart rate was $72 / \mathrm{min}$, and blood pressure was $160 / 90 \mathrm{mmHg}$. The jugular venous pressure was normal, but the liver was tender. There was no peripheral oedema. The cardiac impulse was unremarkable, but auscultation revealed accentuation of the first heart sound, an opening snap, and grade 2 mid-diastolic murmur at the apex.

The electrocardiogram showed sinus rhythm with left atrial hypertrophy. The chest $x$-ray film showed slight pulmonary vascular congestion. The cardiac silhouette suggested left atrial enlargement.

An echocardiogram showed movement of the mitral valve cusps typical of rheumatic mitral

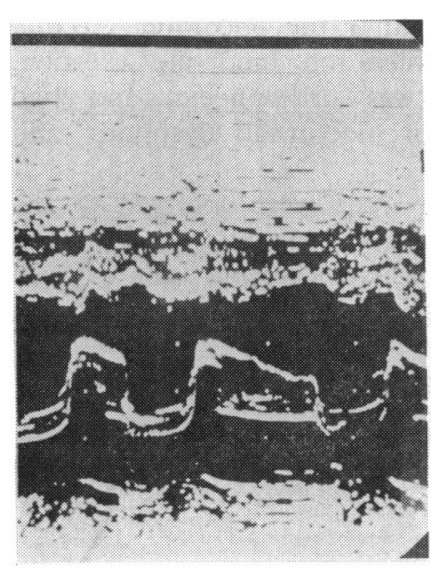

(a)

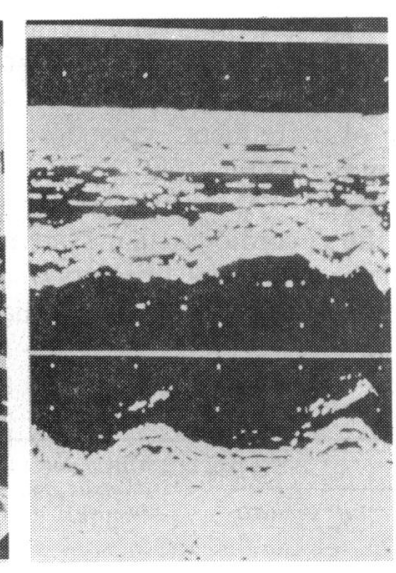

(b)

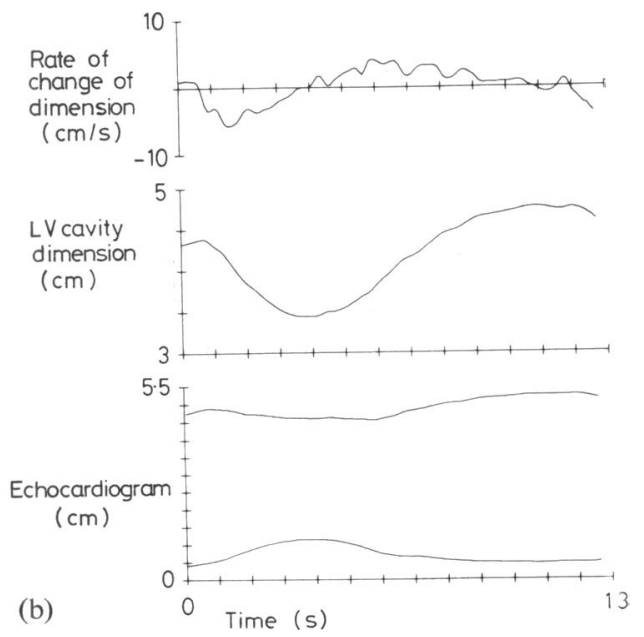

Fig. 4 (a) Case 2: echocardiograms showing mitral valve echoes on the left, and the left ventricular cavity on the right. (b) Case 2: plots of original digitised echocardiogram, the left ventricular cavity dimension, and its rate of change. 
stenosis, and peak diastolic rate of change of transverse dimension was reduced. Increase in dimension at a slow rate proceeded throughout diastole without either a rapid filling phase or an increase at the time of atrial systole. End-diastolic dimension was $5.2 \mathrm{~cm}$.

Cardiac catheterisation was performed because of the suspicion of additional left ventricular disease. The mean mitral valve gradient was $3 \mathrm{mmHg}$ and the left ventricular end-diastolic pressure was raised to $20 \mathrm{mmHg}$. The left ventricular cineangiogram showed a normal pattern of contraction with ejection fraction 70 per cent.

$\mathrm{He}$ was referred for open exploration. The surgeon reported the valve to be severely stenosed with an orifice of less than $1 \mathrm{~cm}$, and the chordae were shortened. Open mitral valvotomy was performed, since when he has been asymptomatic.

\section{Discussion}

We report 3 patients who presented with mitral stenosis and breathlessness, in whom the results of haemodynamic investigations could have led us to consider myocardial disease as the cause of their symptoms. They exemplify the more general problem of distinguishing the mechanical effect of rheumatic heart disease from the 'myocardial factor'. Until recently, the two tests most generally considered reliable in this context have been cardiac catheterisation and left ventricular cineangiography, the former to estimate the pressure gradient, flow, and hence valve area, and the latter to examine wall movement. It has been suggested (Harvey et al., 1955; Fleming and Wood, 1959) that characteristic features of patients with predominant myocardial disease are a mild rise in left atrial pressure and a low cardiac output which fails to increase with exercise, but these are unreliable (Carman and Lange, 1961).

Among reports of the value of simultaneous recordings of left ventricular and left atrial pressures are a number of patients like those reported herein who had severe mitral stenosis with small gradients (Hancock, 1959; Dutrey and Drake, 1961; Hugenholtz et al., 1962; Leach et al., 1962), but they received little attention. If such anomalous findings were discussed at all, they were attributed to tech-

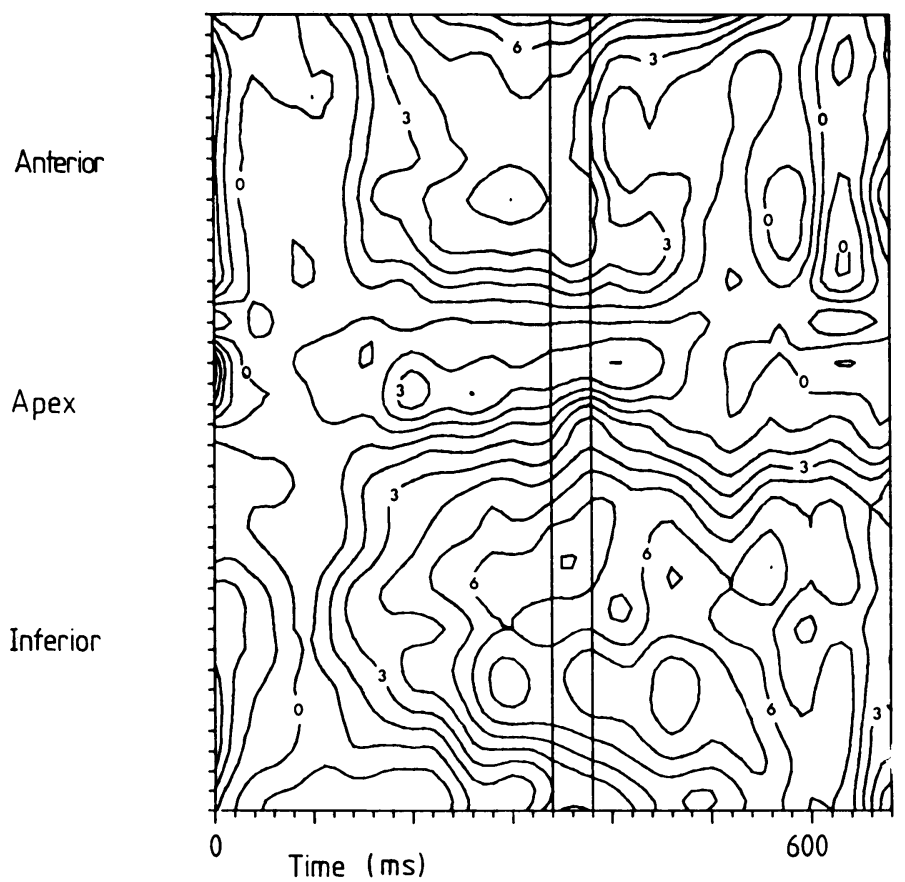

Fig. 5 Case 2: computer display of endocardial movement in all regions of the angiographic cavity during a single cardiac cycle. Each contour line represents $1 \mathrm{~mm}$ movement. The first vertical time marker indicates endsystole and the second mitral valve opening. The diastolic contour lines are spaced widely and evenly, similar to those in systole, indicating that outward movement is slow and persists throughout diastole. 
nical factors until Feigenbaum and co-workers (1966) argued that they indicated 'abnormal ventricular compliance', either as a consequence of rheumatic carditis, or because of the effect on the adjacent myocardium of fibrosis and stiffening of the posterior mitral leaflet and chordae, already described by Grant (1953) in necropsy specimens. Support for the latter hypothesis is provided by observations of regional abnormalities of wall movement in left ventricular cineangiograms (Heller and Carleton, 1970). Thus the unusual findings in the present patients are in keeping with previous observations in suggesting the need to modify the traditional 'bottle-neck' model of the effects of mitral stenosis on the circulation, to reconsider the effects of this condition on left ventricular wall movement, and to review the significance of the left ventricular end-diastolic pressure.

Mitral stenosis affects left ventricular wall movement in two ways. Characteristically slow and protracted filling (Heller and Carleton, 1970) is reflected by the pattern of endocardial movement in all regions and is thus easily demonstrable on the echocardiogram (Gibson and Brown, 1973; St. John Sutton et al., 1977) or by angiography. Fig. 5 shows a display of left ventricular endocardial movement around the whole perimeter of the cavity from the left ventricular cineangiogram of case 2 . The pattern of change in endocardial position or cavity dimension, however displayed, is not the normal biphasic curve corresponding to rapid filling followed by diastasis, but instead change is gradual and persists at close to its maximum rate throughout diastole. In addition, regional abnormalities of wall movement may be demonstrated in many patients, usually involving the inferobasal segment adjacent to the mitral valve, and less frequently other regions also (Heller and Carleton, 1970; Curry et al., 1972; Horwitz et al., 1973). Though this second type of abnormality was not pronounced in any of our 3 patients, the fact that focal abnormalities may occur indicates the existence of factors besides merely inflow obstruction governing wall movement during filling.

The high left ventricular diastolic pressure is further evidence that in these patients filling was influenced by factors below mitral valve level. The significance of this finding in relation to myocardial disease is not straightforward (Braunwald and Ross, 1963) and it is not necessarily the case that, as implied by Feigenbaum, the myocardium is inelastic. The normal mechanism of filling is such that the majority of the diastolic increase in cavity size, which occurs during rapid filling, is achieved with minimal increase in wall stress (Fig. 6) (Gibson and Brown, 1974; Rankin et al., 1977), and it is only

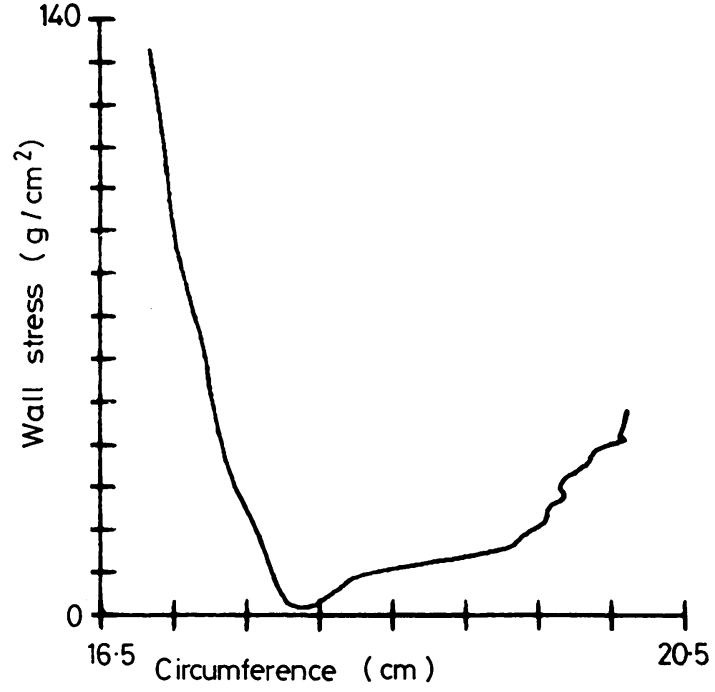

Fig. 6 Diastolic stress-strain relation in a normal subject estimated from simultaneous recordings of left ventricular pressure and echocardiogram.

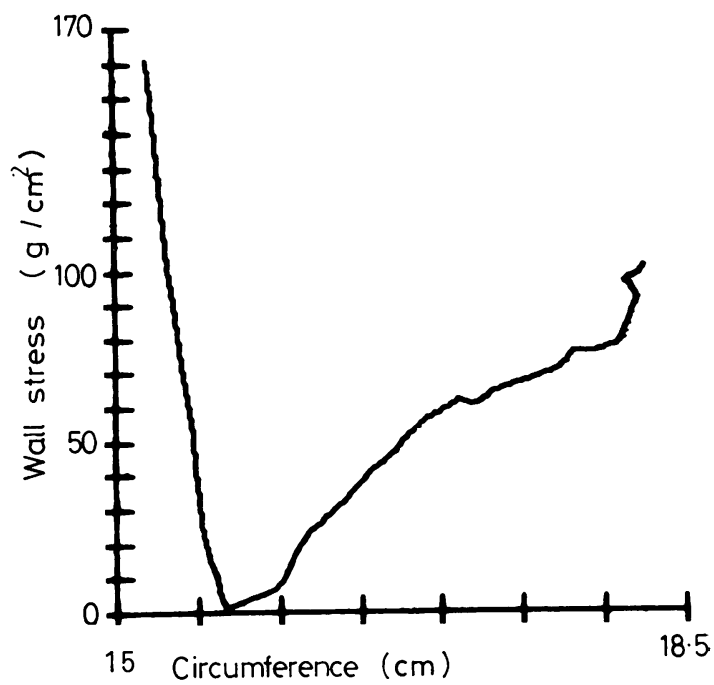

Fig. 7 Case 2: diastolic stress-strain relation obtained as in Fig. 6. After ventricular relaxation, wall stress increases steeply, even at small cavity size.

during the latter part of diastole and over a short range of dimension that the myocardium exhibits linear elastic behaviour. It follows that a rise in the end-diastolic pressure can be the result of more than one kind of abnormality. For example, decreased compliance, resulting from myocardial hypertrophy, can be measured as an increase in slope of the last part of the stress strain relation, and leads to a high value of end-diastolic wall stress. Alternatively the 
same high value could be associated with normal modulus of elasticity and absence or attenuation of the middle part of the curve. This is exemplified by case 2 , in whom the proportional relation between wall stress and strain begins after only a small increase in dimension, so that though the slope is not increased, at the end of diastole wall stress is high (Fig. 7). This is not the effect of reduced compliance, nor is it the result of abnormal viscosity, since viscous forces should be lessened in a situation where filling rate is reduced, and it is therefore difficult to conceive of an explanation in terms of altered material properties of the myocardium. The alternative, which is in keeping with the angiographic evidence, and with the knowledge that surgery effectively relieved symptoms, is that there is an architectural abnormality of the ventricle, the result of rheumatic disease, which affects diastolic function by disruption of a mechanism which normally permits rapid filling.

It seems then that an effect on left ventricular wall mechanics predominated over obstruction at valve level in determining the findings at cardiac catheterisation. The anatomical basis for this is unknown, for the patients are living, but it is to be noted that Grant (1953) described myocardial abnormalities in this condition affecting regions of the left ventricular wall which had been splinted by fibrosis and stiffening of the subvalve apparatus. Regional abnormalities of function may influence the diastolic properties of the whole ventricle in other conditions besides mitral valve disease, for example coronary artery disease, where again a rise in the left ventricular diastolic pressure need not reflect global alteration in myocardial compliance. We conclude that in some patients with significant mitral stenosis haemodynamic data, even when technically above reproach, may be misleading. The critical abnormality for assessing severity appears to be the disturbance of filling, apparent in the pattern of endocardial movement. This is demonstrable by echocardiography in the majority of patients, and if not then it may be shown with a left ventricular cineangiogram. As echocardiographic investigation becomes more prevalent and catheterisation is required less frequently patients such as these may cease to be recognised and will no longer cause diagnostic uncertainty.

We thank Dr R. V. Gibson and Dr M. Honey for permission to report on their patients. Dr Honey performed the cardiac catheterisation in case 1 .

\section{References}

Braunwald, E., Moscovitz, H. L., Amram, S. S., Lasser, R. P., Sapin, S. O., Himmelstein, A., Ravitch, M. M., and Gordon, A. J. (1955). The hemodynamics of the left side of the heart as studied by simultaneous left atrial, left ventricular, and aortic pressures; particular reference to mitral stenosis. Circulation, 12, 69-81.

Braunwald, E., and Ross, J., Jr. (1963). The ventricular enddiastolic pressure. American fournal of Medicine, 34, 147-150.

Carman, G. H., and Lange, R. L. (1961). Variant hemodynamic patterns in mitral stenosis. Circulation, 24, 712-719.

Curry, G. C., Elliott, L. P., and Ramsey, H. W. (1972). Quantitative left ventricular angiocardiographic findings in mitral stenosis. American fournal of Cardiology, 29, 621-627.

Dutrey, D. E., and Drake, E. H. (1961). Preoperative diagnosis of acquired valvular disease. American fournal of Cardiology, 8, 319-327.

Feigenbaum, H., Campbell, R. W., Wunsch, C. M., and Steinmetz, E. F. (1966). Evaluation of the left ventricle in patients with mitral stenosis. Circulation, 34, 462-472.

Fleming, H. A., and Wood, P. (1959). The myocardial factor in mitral valve disease. British Heart fournal, 21, 117-122.

Gibson, D. G., and Brown, D. (1973). Measurement of instantaneous left ventricular dimension and filling rate in man, using echocardiography. British Heart fournal, 35, 1141-1149.

Gibson, D. G., and Brown, D. J. (1974). Relation between diastolic left ventricular wall stress and strain in man. British Heart Fournal, 36, 1066-1077.

Gorlin. R., and Gorlin, S. G. (1951). Hydraulic formulae for calculation of the area of the stenotic mitral valve, other cardiac valves, and central circulatory shunts. I. American Heart Fournal, 41, 1-29.

Grant, R. P. (1953). Architectonics of the heart. American Heart fournal, 46, 405-431.

Hancock, E. W. (1959). Assessment of mitral valve disease by left heart catheterization. British Heart fournal, 21, 389-400.

Harvey, R. M., Ferrer, M. I., Samet, P., Bader, R. A., Bader, M. E., Cournand, A., and Richards, D. W. (1955). Mechanical and myocardial factors in rheumatic heart disease with mitral stenosis. Circulation, 11, 531-551.

Heller, S. J., and Carleton, R. A. (1970). Abnormal left ventricular contraction in patients with miral stenosis. Circulation, 42, 1099-1110.

Horwitz, L. D., Mullins, C. B., Payne, R. M., and Curry, G. C. (1973). Left ventricular function in mitral stenosis. Chest, 64, 609-614.

Hugenholtz, P. G., Ryan, T. J., Stein, S. W., and Abelmann, W. H. (1962). The spectrum of pure mitral stenosis: hemodynamic studies in relation to clinical disability. American fournal of Cardiology, 10, 773-784.

Leach, J. K., Friedlich, A. L., Myers, G. S., Sanders, C. A., and Scannell, J. G. (1962). Usefulness and limitations of left heart catheterization in mitral disease. American fournal of Cardiology, 10, 57-61.

Rankin, J. S., Arentzen, C. E., McHale, P. A., Ling, D., and Anderson, R. W. (1977). Viscoelastic properties of the diastolic left ventricle in the conscious dog. Circulation Research, 41, 37-45.

Robertson, J. D., and Reid, D. D. (1952). Standards for the basal metabolism of normal people in Britain. Lancet, 1, 940-943.

St. John Sutton, M. G., Traill, T. A., Ghafour, A. S., Brown, D. J., and Gibson, D. G. (1977). Echocardiographic assessment of left ventricular filling after mitral valve surgery. British Heart fournal, 39, 1283-1291.

Upton, M. T., Gibson, D. G., and Brown, D. J. (1976). Instantaneous mitral valve leaflet velocity and its relation to left ventricular wall movement in normal subjects. British Heart fournal, 38, 51-58.

Requests for reprints to $\mathrm{Dr} \mathrm{T}$. A. Traill, Brompton Hospital, Fulham Road, London SW3 6HP. 